\title{
Implicações biopsicossociais em vítimas de acidente de trânsito que cursaram com deficiência adquirida ${ }^{1}$ \\ Biopsychosocial implications in traffic accident victims who course with acquired disability Implicaciones biopsicosociales en víctimas de accidentes de tráfico que cursan con discapacidad adquirida
}

Fabiulla Costa Da Silva ${ }^{2}$, Alana Libania de Souza Santos ${ }^{3}$, Ricardo Bruno Santos Ferreira ${ }^{4}$, Luma Costa Pereira

\section{RESUMO}

Objetivo: compreender as implicações biopsicossociais em vítimas de acidentes de trânsito que adquiriram deficiência. Método: Trata-se de uma pesquisa descritiva com abordagem qualitativa, desenvolvida em um Centro de Saúde Universitário de um município de referência do Território Sertão Produtivo da Bahia, Brasil, com doze vítimas de acidentes de trânsito atendidas com deficiência adquirida. As informações foram coletadas por meio de entrevista semiestruturada, no período de agosto a setembro de 2018. Para a análise das informações, foi utilizada a técnica de análise de conteúdo. Resultados: No aspecto físico, o acidente de trânsito gerou restrição de autonomia, limitação física para realização de atividades básicas da vida diária, deterioração de habilidades e perda da independência. No aspecto psicológico, o acidente causou sofrimento psíquico, representado por sentimentos de desesperança, tristeza, estresse, raiva, culpa e medo, intensificados pela instabilidade econômica. Além disso, o acidente teve grande impacto social, como restrições ao trabalho, estudo e lazer. Conclusão: a deficiência adquirida em um acidente de trânsito tem repercussões importantes na vida das vítimas, tanto física quanto psicossocialmente. A formação de redes de apoio compostas por familiares e equipe de saúde é fundamental para dar o suporte necessário às pessoas nesta nova condição de vida.

DESCRITORES: Acidente de trânsito; Pessoas com deficiência; Saúde mental; Reabilitação; Enfermagem.

\footnotetext{
${ }^{1}$ Data de recepção: 22 de maio de 2020

Data de aceitação: 3 de outubro de 2020

${ }^{2}$ Enfermeira, graduanda em enfermagem pela Universidade do Estado da Bahia, Guanambi (BA), Brasil.

E-mail: fabiulla0608@gmail.com. ORCID: https://orcid.org/0000-0001-5713-389X

${ }^{3}$ Mestra em enfermagem. Professora da Universidade do Estado da Bahia (DEDC-XII). Guanambi (BA), Brasil.

E-mail: lana_libania@hotmail.com. ORCID: http://orcid.org/0000-0002-6503-8742

${ }^{4}$ Mestre em Enfermagem. Professor da Universidade do Estado da Bahia (DEDC-XII). Guanambi (BA), Brasil.

E-mail: ricardobrunoenf@gmail.com ORCID: https://orcid.org/0000-0003-0614-4817

${ }^{5}$ Mestra em Enfermagem e Saúde. Professora da Universidade Estadual de Feira de Santana - UEFS. Feira de Santana (BA), Brasil. Email: lumacosta88@hotmail.com ORCID: https://orcid.org/0000-0002-6366-0212
} 


\section{Revista Electrónica Enfermeria Actual en costa Rica}

Objective: to understand the biopsychosocial implications in victims of traffic accidents who had acquired disability. Method: This is a descriptive research with a qualitative approach, developed in a University Health Center in a reference city of the Sertão Productivo Territory of Bahia, Brazil, with twelve victims of traffic accidents who attended with acquired disabilities. The information was collected through a semi-structured interview, in the period between August and September 2018. For the analysis of the information, the content analysis technique was used. Results: In the physical aspect, the traffic accident generated the restriction of autonomy, physical limitation to carry out basic activities in daily life, deterioration of skills and loss of independence. In the psychological aspect, the accident caused mental suffering, represented by feelings of hopelessness, sadness, stress, anger, guilt and fear, intensified by economic instability. In addition, the accident had a great social impact, such as restrictions on work, study and leisure. Conclusion: the disability acquired by a traffic accident has important repercussions on the lives of the victims, both physically and psychosocially. The formation of support networks made up of family members and the health team is essential to provide the necessary support to people in this new condition of life

DESCRIPTORS: Traffic accident; Disabled people; Mental health; Rehabilitation; Nursing.

\section{RESUMEN}

Objetivo: comprender las implicaciones biopsicosociales en víctimas de accidentes de tráfico que habían adquirido discapacidad. Método: Se trata de una investigación descriptiva con enfoque cualitativo, desarrollada en un Centro Universitario de Salud en una ciudad de referencia del Territorio Sertão Productivo de Bahía, Brasil, con doce personas víctimas de accidentes de tránsito que asistieron con discapacidad adquirida. La información fue recolectada mediante entrevista semiestructurada, en el período comprendido entre agosto y septiembre de 2018. Para el análisis de la información se utilizó la técnica de análisis de contenido. Resultados: En el aspecto físico, el accidente de tránsito generó la restricción de autonomía, limitación física para realizar actividades básicas en la vida diaria, deterioro de habilidades y pérdida de independencia. En el aspecto psicológico, el accidente provocó sufrimiento mental, representado por sentimientos de desesperanza, tristeza, estrés, rabia, culpa y miedo, intensificados por la inestabilidad económica. Además, el accidente tuvo un gran impacto social, como restricciones en el trabajo, el estudio y el ocio. Conclusión: la discapacidad adquirida por un accidente de tráfico tiene repercusiones importantes en la vida de las víctimas, tanto física como psicosocialmente. La formación de redes de apoyo integradas por familiares y equipo de salud es fundamental para brindar el apoyo necesario a las personas en esta nueva condición de vida.

Descriptores: Accidente de tránsito; Enfermería Personas con deficiencia; Rehabilitación; Salud mental. 


\section{Revista Electrónica Enfermeria Actual en costa Rica}

\section{INTRODUÇÃO}

Os acidentes de trânsito são atualmente a oitava causa de morte em todo o mundo e representa uma das principais causas de óbitos entre os jovens. Ademais, são responsáveis por sequelas capazes de provocar implicações físicas e psicossociais nos acidentados. O relatório global revelou que, a cada ano, cerca de 1,35 milhão de pessoas morrem em acidentes de trânsito no mundo e 50 milhões de pessoas sobrevivem com sequelas ${ }^{1,2}$.

No Brasil, por exemplo, morreram 36.430 pessoas vítimas de acidente de trânsito apenas em 2017. Dados do Sistema de Informações Hospitalares do Sistema Único de Saúde (SUS) apontam que para cada óbito em acidentes, 25 pessoas sobrevivem com lesões graves e incapacitantes ${ }^{3}$. Além disso, segundo o Departamento Nacional de Trânsito há enorme impacto financeiro relacionado ao elevado pagamento de indenizações, refletindo a extensão da problemática no país ${ }^{4}$.

Os acidentes de trânsito estão entre as causas mais comuns de deficiência adquirida, ficando atrás apenas das doenças crônicas ${ }^{5}$. A deficiência adquirida consiste na perda da estrutura ou da função fisiológica, psicológica ou anatômica que gera restrição para realizar atividades da vida diária ${ }^{6}$. Nesse processo, inúmeros sentimentos são experimentados, a depender da percepção dos acontecimentos, da resiliência, das características de personalidade e da rede de apoio.

A partir do momento da constatação de uma deficiência, inicia-se uma fase que provoca revolução e mudança, não apenas no indivíduo, como também no seio familiar. Essas mudanças atingem aspectos físicos, emocionais, socioeconômicos, espirituais e familiares. Entretanto, pouco se discute sobre as consequências psicológicas e sociais da deficiência adquirida por acidente de trânsito, uma vez que em sua maioria, os estudos abordam apenas as perdas físicas e econômicas.

Assim, esse estudo justifica-se pelos índices elevados de acidente de trânsito no Brasil e no mundo, associado ao impacto biopsicossocial da deficiência adquirida, na vida dos vitimados. Diante disso, surgiu a pergunta de investigação que norteia esse estudo: quais as implicações biopsicossociais em vítimas de acidente de trânsito que cursaram com deficiência adquirida?

Acredita-se que o poderá subsidiar a assistência integral à pessoa vítima de acidentes de trânsito que cursa com deficiência, a partir da identificação de fatores psicobiológicos associados a essa experiência, além de possibilitar a reflexão de estratégias de melhor adaptação frente à deficiência adquirida, contribuindo com ações de promoção à saúde física e mental.

Nesse sentido, este estudo objetiva compreender as implicações biopsicossociais em vítimas de acidente de trânsito que cursaram com deficiência adquirida.

\section{METODOLOGIA}

Trata-se de uma pesquisa descritiva, de abordagem qualitativa, desenvolvida em um Centro de Saúde Universitário conveniado ao Sistema Único de Saúde (SUS), que oferece reabilitação fisioterapêutica à população. O serviço conta também com serviços de Psicologia, Nutrição e ambulatório de Pediatria e Clínica Médica, situado em um 


\section{Revista Electrónica Enfermeria Actual en costa Rica}

município referência em assistência à saúde no Território Sertão Produtivo da Bahia, que abarca 19 cidades, com população estimada em 78.833 mil habitantes ${ }^{7}$.

Participaram do estudo doze pessoas vítimas de acidentes de trânsito que cursaram com deficiência adquirida e que são atendidas no centro universitário para tratamento de reabilitação fisioterápica.

Considerou-se critérios de elegibilidade dos participantes pessoas com deficiência adquirida do tipo motora, que frequentavam o serviço regularmente, constatado pelo comparecimento nas sessões de fisioterapia agendadas durante o período de coleta. Por outro lado, foram excluídos os pacientes que tinham diagnóstico psiquiátrico de Transtorno de Estresse Pós Traumático, informado pelo paciente, para que não fosse induzido a reviver o evento traumático, cujo efeito negativo já é conhecido; e aqueles recém-admitidos, com tempo de admissão inferior a uma semana.

O contato inicial com os participantes foi mediado pela coordenadora do serviço de fisioterapia do centro universitário, que auxiliou na identificação dos pacientes elegíveis para o estudo. Após a sessão de fisioterapia, os pacientes foram abordados individualmente, ocasião em que foi apresentada a proposta do estudo. Após aceite, o participante foi encaminhado para sala reservada para leitura, assinatura do termo de consentimento livre e esclarecido (TCLE) e realização da entrevista.

Após a assinatura do TCLE, a entrevista foi gravada por meio de um aparelho gravador digital e posteriormente, transcrita na íntegra, com a finalidade de manter a fidedignidade das informações. Para preservar o anonimato, os participantes foram identificados pela letra "E" seguida do número em ordem crescente na ordem da entrevista.

As questões norteadoras utilizadas na entrevista desse estudo foram: 1) O que significa para você a deficiência adquirida pelo acidente? 2) Como o acidente interferiu na sua vida? E na sua saúde mental? (familiar, econômica, trabalho, pessoal, social, sexualidade, lazer); 3) Atualmente você tem algum tipo de dor e sofrimento em decorrência do acidente? Descreva-o; 4) Quais suas perspectivas futuras?

A coleta das informações ocorreu nos meses de agosto e setembro de 2018, por meio da técnica de entrevista semiestruturada, guiada por um roteiro contendo questões sóciodemográficas e outras relacionadas ao tema de investigação, com duração média de 15 minutos. As entrevistas foram finalizadas após a constatação da saturação das informações ${ }^{8}$.

Para análise das informações foi utilizada a técnica de análise de conteúdo temático, constituída pelas seguintes etapas: pré-análise, exploração do material e tratamento dos resultados, inferência e interpretação ${ }^{9}$.

\section{Considerações éticas}

O estudo respeitou os aspectos éticos propostos na Resolução n 510 de 2016 do Conselho Nacional de Saúde, que dispõe sobre as normas e diretrizes que regulamentam a pesquisa científica envolvendo seres humanos, sendo aprovado pelo Comitê de Ética em Pesquisa (CEP) do Centro Universitário de Guanambi (UniFG), agosto de 2018 com parecer consubstanciado n. 2.796.460 e CAAE: 85829917.0.0000.8068. 


\section{Revista Electrónica Enfermeria Actual en costa Rica}

\section{RESULTADOS}

Participaram do estudo doze pessoas, sendo oito homens e quatro mulheres, com idade entre 18 e 53 anos. No que diz respeito à situação conjugal, cinco eram solteiros e sete casados. Quanto à situação financeira, todos possuíam renda igual ou inferior a dois salários mínimos, sendo que onze dos doze participantes eram trabalhadores autônomos. A religião predominante foi a católica, com seis participantes.

Em relação às características do acidente de trânsito, os entrevistados sofreram, predominantemente, acidentes utilizando a motocicleta como meio de transporte. A deficiência física apresentada pelos participantes abrangeu perda da mobilidade, com dependência para todas as necessidades básicas. Entre as sequelas físicas apresentadas identificaram-se: politrauma ósseo, traumatismo crânio encefálico e neuropraxia.

Quanto à memória do acidente, apenas um dos entrevistados diz não se recordar do ocorrido, os outros se recordam com exatidão o transcorrer do acidente, a data e os primeiros socorros.

Durante o processo de análise das entrevistas emergiram cinco categorias: 1) limitações físicas impostas pela deficiência adquirida; 2) rede de apoio frente a deficiência adquirida; 3 ) implicações da deficiência adquirida na dimensão psicológica; 4) implicações da deficiência adquirida na dimensão social; 5) reorientação do projeto de vida.

\section{Limitações físicas impostas pela deficiência adquirida}

Os participantes apontaram a deficiência adquirida como evento responsável pela restrição da autonomia e sentimento de impotência, pois eles se veem impossibilitados de realizar atividades rotineiras.

"Limitação, acho que a palavra é essa (risos). Fiquei dependente de tudo, no princípio eu fiquei dependente da minha mãe pra praticamente tudo (...) então é muito ruim você ficar ocupando outra pessoa." (E8)

"Eu fiquei dependendo de outra pessoa no momento que eu fiquei imobilizado, durante 30 dias. Com o braço imobilizado, tinha que ter um cuidado maior comigo, porque eu não podia fazer várias coisas com uma mão [...] você fica assim, impossibilitado de fazer várias coisas." (E6)

"Eu fiquei 90 dias de cama, de cadeira de rodas, sofrendo nas mãos dos outros. Ai eu comecei a andar [...] Está difícil para recuperar, você sente muita dificuldade, tem que ter muita ajuda mesmo [...]." (E4)

"Foi ruim, fiquei três meses parado, dependendo dos outros [...]." (E7)

"Eu fiquei em casa sem poder sair, precisava de ajuda de pessoas pra fazer muitas coisas. Isso psicologicamente me afetou muito." (E5)

Além da dificuldade de adaptação a nova condição de vida com limitações e dependência, a dor física configura-se como um empecilho e um motivo de preocupação para a vítima. 


\section{Revista Electrónica Entermeria actual en costa Rica}

“[sentia] Muita dor porque eu não tinha força nas pernas. Não tinha aquela estabilidade, então dificultou muito pra mim." (E3)

"Tive que parar meus planos, tive que reduzir um pouco. Agora [estou sentindo] dores também, diariamente." (E10)

\section{Rede de apoio frente à deficiência adquirida}

Evidenciou-se que a família, os profissionais de saúde e a religião foram destacados como primordiais no processo de adaptação pós-acidente. Observa-se que em volta do indivíduo com deficiência física se desenvolve uma teia de relações denominada rede de apoio, que tem a finalidade de auxiliar na recuperação e necessidades do acidentado.

“Minha família me apoiou bastante.” (E5)

“Meus pais que me ajudaram bastante.” (E7)

“É isso mesmo, uniu, pelo menos uniu a minha família.” (E9)

“Minha mãe e meu irmão. Meu irmão foi assim meu braço direito, foi o que mais me ajudou.” (E8)

“Minha família me ajudou assim, questão de alimento, lavar roupa pra mim [...]”. (E1)

"Faço dois dias de fisioterapia na semana, agora as dores vão passando, vai acostumando mais[...]” (E10)

“Estou vendo muito resultado depois da fisioterapia.” (E3)

“Também veio uns problemas na família e abalou ainda mais. Mas agora estou recuperando [...], estou tendo muita ajuda aqui na fisioterapia. Gostei muito da equipe." (E4)

“Graças a Deus minha recuperação, Deus me deu meus movimentos de volta, graças a Deus [...].” (E12)

\section{Implicações da deficiência adquirida na dimensão psicológica}

Verifica-se que a mudança na condição física de forma abrupta despertou nos participantes os sentimentos de culpa, preocupação, ansiedade, medo e tristeza. Ao serem indagados sobre a saúde psicológica, os participantes apontaram o acidente como algo traumático.

“É bem traumático, fisicamente e psicologicamente.” (E5)

"Fiquei muito preocupada, ansiosa (...) eu passei no especialista de joelho e ele falou que eu ia ter que fazer cirurgia. Foi onde veio mais preocupação, não dormia, ansiosa, preocupada.” (E3) 


\section{Revista Electrónica Enfermeria Actual en costa Rica}

"Fiquei muito preocupado com as contas, entendeu? Ansioso." (E7)

"Tem a fase do estresse, todo mundo que passa por isso tem uma hora que fica extremamente estressada. É aquela situação de não estou aguentando mais, já estou pra ficar doida [...]” (E8)

"Muita tristeza porque nunca mais você vai ser o que você era antes. Tem muita dificuldade na recuperação." (E4)

"Um choque muito grande sabe, porque até então, tudo, qualquer coisinha assim é medo [...] coração bater mais forte, sabe." (E10)

"Até hoje, moto pra mim (risos), eu não quero montar não [...] até pra voltar para o serviço eu estou pensando. A gente fica assim, com um pouquinho de trauma para andar de moto." (E12)

"Você fica pensando no que você poderia ter feito pra evitar aquilo, você fica se culpando, tem hora que você fica pensando numas coisas, mas [...] tem que seguir a vida." (E6)

\section{Implicações da deficiência adquirida na dimensão social}

Observa-se que houve as implicações da deficiência adquirida no âmbito social, com identificação de mudanças nos hábitos diários dos vitimados, principalmente no que diz respeito à atividade laboral, estudos e lazer.

"Foi muito dificil, porque assim, eu trabalho pra mim mesma, entendeu? Então, eu vou a domicílio, sou manicure." (E3)

"Vai fazer três meses agora e eu estou parado fazendo fisioterapia. Interferiu muito, estou impossibilitado de trabalhar no momento [...]" (E6)

"Interferiu porque eu fiquei um bom tempo parado, sem rendimento nenhum, não podia fazer bico, por que se eu fizesse bico eu tinha que voltar para o serviço de novo. Eu fiquei uma temporada boa, encostei no INSS $[\ldots] . "(E 1)$

"Representa que eu fiquei parado, não posso trabalhar por enquanto, porque no serviço, o pedreiro pega peso [...] A gente fica preocupado porque está parado e tem que trabalhar." ( E11)

"Tem horas que o pessoal vai cumprimentar alguma coisa e acham que eu estou com raiva porque en fico com a cara séria o tempo todo". (E2) (cursou com paralisia facial)

“Eu perdi o São João. Todas as festas eu perdi." (E9)

"Eu não parava em casa, porque eu passava o dia trabalhando e a noite eu tinha faculdade. Também tem a questão da minha noiva, eu saia com ela, essas coisas. A gente sente falta por que era quase todo final de semana, a gente ia para a praça, a gente ia fazer alguma coisa." (E10) 


\section{Revista Electrónica Entermeria actual en costa Rica}

"Sinto algumas dificuldades para me locomover, para trabalhar, não consigo mais praticar esportes como eu fazia, então afeta nesse sentido [...] Algumas pessoas se afastam né, mas quem realmente importa quer estar mais próximo." (E5)

Em consequência da impossibilidade de trabalhar, surgiram dificuldades econômicas, que foram motivo de ansiedade e preocupação para os entrevistados. Dessa maneira, a instabilidade financeira teve implicações psicológicas, pois a incerteza da renda fez com que os entrevistados ficassem em estado de apreensão.

"Minha vida econômica mudou um pouco [...] Fiquei muito preocupado com as contas entendeu? Ansioso." (E7)

Foi difícil porque na hora que eu quebrei, eu preocupei muito com as dívidas (risos). Estava devendo muito, então é a primeira coisa que vem na cabeça. Como é que eu vou fazer meu Deus? Trabalhar com a perna quebrada, você pensa mil coisas, ai não deixa de não preocupar. Até hoje eu preocupo, porque não tem renda nenhuma. (E4)

\section{Reorientação do projeto de vida}

Percebe-se que o acidente trouxe consigo uma interrupção abrupta no projeto de vida dos vitimados, com necessidade de reorganizaçãodo modo de viver e modificação na maneira de se relacionar com outras pessoas. Além disso, a perda e a experiência de quase morte serviram de alicerce para a ressignificação da vida e construção de resiliência.

"Significou uma interrupção nos meus planos, na minha rotina (pausa), nas coisas que eu fazia e na minha normalidade, porque até hoje eu não voltei ao normal, (pausa) é isso." (E5)

"Você fica meio abalado, você não espera acontecer um acidente de repente, estava trabalhando, tinha projetos na vida pra você fazer alguma coisa, ai atrapalha." (E6)

"Veio pra refletir um pouco, primeiramente aprendi que a gente deve agradecer, porque durante esses oito meses eu senti muita falta do pé. Passei a entender o significado de ter, agradecer o que eu tenho, sabe!" (E10)

"Você percebe o valor da liberdade porque nessa época você fica castrada, você fica com sua vida castrada e ai você começa a dar valor às coisas". (E8)

"Eu espero que eu recupere, [...] [quero] trabalhar muito. Penso em ajudar muito as pessoas porque eu sempre gosto de ajudar. [Quero] ter uma vida normal." (E4)

"[Espero] melhorar a situação de vida, [...] [quero] recuperar esse tempo que eu fiquei parado.” (E7) 


\title{
Revista Electrónica Enfermeria Actual en costa Rica
}

\begin{abstract}
"[Quero] voltar a morar só, conseguir um novo emprego numa área que eu realmente me identifico [...], e então assim, tocar a vida." (E8)
\end{abstract}

\section{DISCUSSÃO}

Nesse estudo, nota-se predominância de pessoas do sexo masculino, algo também encontrado em outros estudos que avaliam o perfil de pessoas vítimas de acidentes de trânsito, onde se verifica inúmeros fatores culturais (machismo, relações de poder, agressividade, entre outros) que justificam essa prevalência ${ }^{10,11}$. Evidencia-se também respaldo na literatura acerca da prevalência na utilização de motocicletas, devido seu baixo custo ${ }^{12,2}$.

A partir dos resultados foi possível perceber que o impacto de lesões em acidentados no trânsito interfere na mobilidade e, consequentemente, na capacidade de realização de atividades. É comum, nesse aspecto, a existência de dependência na vida pessoal, profissional e social ${ }^{13}$.

Tal constatação corrobora com os achados de um estudo realizado no Peru, onde se evidenciou que 44,7\% das pessoas com algum tipo de deficiência adquirida por acidente de trânsito dependem de alguém para desenvolver suas atividades diárias ${ }^{14}$. Essa limitação provoca reflexos nas dimensões biopsicossociais, uma vez que afeta as atividades diárias básicas como mobilidade, saúde e autonomia para as atividades cotidianas ${ }^{15}$.

Acrescenta-se ainda que as lesões oriundas dos acidentes de trânsito comprometem a percepção do indivíduo em relação às suas condições de vida, bem-estar psicológico, capacidade para o trabalho, e consequentemente, a qualidade de vida ${ }^{15}$. A dependência funcional pode provocar o aparecimento de alterações psicológicas como: tristeza, apatia, culpa, tornando estas pessoas irritadas, intolerantes e ansiosas ${ }^{16}$.

É nesse contexto que ganha importância a formação da rede de apoio. O apoio mais significativo advém da família nuclear, que se ocupa dos cuidados básicos e das prerrogativas do futuro. As relações com amigos, colegas de trabalho e profissionais de saúde também constituem fontes significativas de apoio, que complementam o cuidado familiar. Esse conjunto interage entre si e abarcam questões relacionadas à ajuda financeira e apoio emocional, contribuindo tanto para o enfrentamento da vida com a deficiência quanto no aprimoramento da atenção prestada a pessoa com deficiência física ${ }^{17}$.

Essa evidência é semelhante ao resultado obtido em um estudo realizado no sul do Brasil, que identificou que a rede de apoio formada por familiares e profissionais de saúde auxilia na construção de atitudes positivas que reforçam a estima e a confiança dos sujeitos, acarretando assim sentimentos de conforto ${ }^{18}$.

Quanto aos profissionais, o apoio abrange não apenas o ponto de vista técnico e instrumental, mas também no aspecto emocional através do apoio moral e afetivo. É possível que a intervenção dos profissionais envolvidos, juntamente com os membros que compõem a rede de apoio, beneficiem a adaptação da pessoa que experiencia a deficiência física, reativando seus laços sociais ${ }^{19-2}$.

Entretanto, é necessário pontuar que aproximadamente $82,3 \%$ das pessoas com deficiência adquirida não conseguem realizar atividade de reabilitação física com uma equipe de saúde ${ }^{14}$. Entre os fatores que podem justificar 


\section{Revista Electrónica Enfermeria Actual en costa Rica}

a falta de acesso à reabilitação física destaca-se a instabilidade financeira, fazendo com que os pacientes optem pela subsistência da família em detrimento do investimento na sua própria reabilitação ${ }^{13}$.

Salienta-se que, apesar da tristeza e do impacto ocasionado pelo acidente, houve também a oportunidade de analisar a vida de outra forma, traçando novos projetos e tendo a esperança de reaver a mobilidade de antes da lesão. Essa reconstrução envolve, por exemplo, o controle do estresse e ansiedade, sintomas comuns em pacientes acidentados ${ }^{20}$. Acrescenta-se ainda a necessidade de superação do sentimento de desesperança, presente no transtorno de adaptação, onde o indivíduo manifesta uma resposta emocional por conta do estresse gerado pela falta de alternativas ${ }^{21}$.

A reação aguda ao estresse é a resposta mais comum e conhecida entre acidentados. É natural, por exemplo, que nos primeiros dias após um acidente, não se tenha vontade de dirigir, pilotar ou andar em outro meio de transporte. Essa reação agudizada do estresse aumenta a ansiedade e promove sintomas como dificuldade de respirar, aumento da frequência cardíaca, agitação, perda de apetite e insônia ${ }^{22}$.

Soma-se ainda a possibilidade de evolução para o transtorno de estresse pós-traumático (TEPT), no qual a pessoa reage à experiência com medo e impotência, revivendo persistentemente o acontecido em sonhos e pensamentos e manifestando nervosismo, aumento na pressão arterial, palpitações, sudorese, rubor e tremores ${ }^{21}$.

Dentre os participantes, esse estresse pode ser potencializado porque a maioria dos entrevistados não possuía vínculo formal de trabalho no momento do acidente. Com isso, acredita-se que a limitação na atividade laboral tem como consequência o sentimento de impotência devido a condição financeira desfavorável, secundária a ausência de vínculo trabalhista no momento do acidente ${ }^{23}$.

Cabe mencionar, que através dos relatos é possível notar que a reação frente ao acidente e a experiência que se leva desse acontecimento é individual e por isso, varia de pessoa para pessoa. Algo semelhante ao encontrado em outro estudo $^{24}$.

As repercussões da deficiência adquirida no âmbito da atividade laboral e nas relações sociais enfatizam a necessidade de um olhar diferenciado no cuidado, buscando integrar a vítima na sociedade. Nesse aspecto, o diálogo entre a equipe de saúde e o paciente permite compreender, além dos aspectos físicos da deficiência, o modo como ele enfrenta a nova condição nas relações pessoais e no afastamento do trabalho.

É notório que o acidente é visto como um evento inesperado, em que as pessoas não acreditam que possam acontecer consigo ou com pessoas próximas. A ideia prevalente, semelhante a outros achados, é que se trata de um evento distante, o que faz com que a segurança seja colocada em segundo plano ${ }^{24}$.

Nesse contexto, a maneira como o acidente é abordado nas falas demonstra o grande impacto no projeto de vida dos vitimados. A forma de tratá-lo como empecilho ao andamento de suas vidas ressalta o sentimento de tristeza e perda. Por isso, acredita-se que muitas pessoas que passam por esse evento precisam de uma atenção psicológica focada em ajudá-las a dar sentido a suas vidas e buscar ressignificar a limitação física ${ }^{22}$.

Para tanto, conhecer a capacidade de enfrentamento e resiliência dos vitimados auxiliando no desenvolvimento de ações envolvendo educação em saúde, além de influenciar o nível de adesão ao tratamento. Desse modo, cada fator envolvido no processo de reabilitação passa a ser alvo de intervenção da equipe multiprofissional ${ }^{2}$. 


\section{Revista Electrónica Enfermeria Actual en costa Rica}

Acredita-se assim que a reorganização do projeto de vida e a ressignificação do trauma é fundamental para a construção de otimismo e confiança em um desfecho positivo no tratamento e na reabilitação, uma vez que contribui para reconquista da independência e superação dos impactos físicos e psicológicos relacionados ao trauma.

O estudo realizado apresentou limitações quanto ao acesso à população pesquisada, devido a inexistência de um serviço multidisciplinar específico para vítimas de traumas. Dessa forma, houve uma dificuldade na captação desses indivíduos.

Outra limitação importante foi o número reduzido de estudos voltados aos aspectos psicológicos das vítimas de acidentes de trânsitos que cursaram com deficiência adquirida. Por isso, o estudo levanta a necessidade de desenvolvimento de novas pesquisas, em diferentes realidades para verificar o presente objeto.

\section{CONCLUSÃO}

A deficiência adquirida por acidente de trânsito traz repercussões significativas na vida das vítimas, tanto física quanto psicologicamente. No aspecto físico, evidenciamos a restrição da autonomia, limitação física para execução de atividades básicas na vida diária, comprometimento de habilidades e perda de independência. Já no aspecto psicológico, o acidente provocou sofrimento mental, representado pelos sentimentos de falta de esperança, tristeza, estresse, raiva, culpa e medo.

Além disso, o acidente provoca impacto social e financeiro para os vitimados. Por isso, a formação de redes de apoio compostas por familiares e equipe de saúde é necessária para dar o suporte necessário aos indivíduos nessa nova condição de vida. Ademais, é fundamental aumentar o acesso de vítimas de acidente de trânsito aos serviços multiprofissionais que auxiliem no cuidado de forma holística.

Acredita-se que as evidências podem contribuir com os profissionais de saúde na busca pela compreensão dos contextos que envolvem a deficiência adquirida. A partir disso, é possível desenvolver ações que busquem atender as necessidades dessa população, focada não apenas na dimensão física do indivíduo, mas também nas dimensões psicossocial e espiritual.

\section{REFERÊNCIAS BIBLIOGRÁFICAS}

1. World Health Organization. Global status report on road safety 2018. Geneva: World Health Organization; 2018.

2. Marth MP, Soares ES. Direito integral à saúde: estudo com sujeitos envolvidos em acidentes de trânsito sob a percepção do serviço social. Serv. Soc. \& Saúde. 2017; 16 (1): 99-118. DOI: https://doi.org/10.20396/sss.v16i1.8651475

3. Brasil. Ministério da Saúde. Departamento de Informática do Sistema Único de Saúde (DATASUS): Sistema de Informações sobre Mortalidade. Brasília: Ministério da Saúde; 2018. 


\section{Revista Electrónica Enfermeria Actual en costa Rica}

4. Seguradora Líder. Boletim estatístico da seguradora líder-DPVAT, maio de 2018, 2018. https://www.seguradoralider.com.br/Documents/boletim-estatistico/BOLETIM-VOL05-MAIO-2018.pdf

5. World Health Organization. Community Based Rehabilitation: CBR Guidelines. Geneva: World Health Organization; 2010.

6. Malta DC, Stopa SR, Canuto R, Gomes NL, Mendes VLF, Goulart BNG, et al. Prevalência autorreferida de deficiência no Brasil, segundo a Pesquisa Nacional de Saúde, 2013. Ciênc. saúde coletiva. 2016; 21(10): 3253-3264. DOI: https://doi.org/10.1590/1413-812320152110.17512016

7. Brasil. Instituto Brasileiro de Geografia e Estatística. Resultados do Censo 2010- Guanambi. Rio de janeiro. 2017; 4.4.9. https://cidades.ibge.gov.br/brasil/ba/guanambi/panorama.

8. Minayo MCS. O desafio do conhecimento: pesquisa qualitativa em saúde. 13. ed., São Paulo: Hucitec, 2013

9. Bardin L. Análise de Conteúdo. Lisboa: Edições 70, 2016.

10. Souto CC, Reis FKW, Bertolini RPT, Lins RSMA, Souza SLB. Perfil das vítimas de acidentes de transporte terrestre relacionados ao trabalho em unidades de saúde sentinelas de Pernambuco, 2012 - 2014. Epidemiol. Serv. Saúde. 2016; 25 (2): 351-361. https://doi.org/10.5123/s1679-49742016000200014

11. Moreira MR, Ribeiro JM, Motta CT, Motta JIJ. Mortalidade por acidentes de transporte de trânsito em adolescentes e jovens, Brasil, 1996-2015: cumpriremos o ODS 3.6?. Ciênc. saúde coletiva. 2018; 23 ( 9 ): 2785-2796. http://dx.doi.org/10.1590/1413-81232018239.17082018.

12. Belmonte LM, Lange BA, Silva CM, Silva TO, Belmonte LAO. Levantamento do perfil das vítimas de acidentes motociclísticos internadas em um Hospital Público de Santa Catarina. Rev. Saúde Públ. 2017; 10 (1): 8-22. http://revista.saude.sc.gov.br/index.php/inicio/article/view/401/0.

13. Nolasco TR, Andrade SMO, Silva BAK. Capacidade funcional de vítimas de acidentes de trânsito em Campo Grande, Mato Grosso do Sul. Ensaios Cienc. 2016; 20 (2): 104-110. https://doi.org/10.17921/14156938.2016v20n2p104-110

14. Gutiérrez C, Romaní F, Wong-Chero P, Montenegro-Idrogo JJ. Perfil epidemiológico de La discapacidad por accidentes de trânsito em el Perú, 2012. Rev Peru Med Exp Salud Publica. 2014; 31 (2): 267-73. http://www.scielo.org.pe/scielo.php?script=sci_arttext\&pid=S1726-46342014000200011\&lng=es

15. Silveira JZM, Souza JC. Sequelas de acidentes de trânsito e impactos na qualidade de vida. Rev. Saúde e Pesq. 2016; 9 (2): 373-380. https://doi.org/10.17765/2176-9206.2016v9n2p373-380

16. Valença TDC, Lima PV, Chaves RN, Santana ES, Reis LA. Repercussões sociais da aquisição de uma deficiência física na vida de idosos. Revista Kairós Gerontologia. 2017; 20 (1): 41-55. https://doi.org/10.23925/2176-901X.2017v20i1p41-55

17. Cruz DM, Nascimento LRS do, Silva DMGV, Schoeller SD. Redes de apoio à pessoa com deficiência física. Cienc. Enferm. 2015; 21 (1): 23-33. http://dx.doi.org/10.1590/1413-81232014201.19012013 


\section{Revista Electrónica Enfermeria Actual en costa Rica}

\section{www.revenf.ucr.ac.cr}

18. Brignol P, Schoeller SD, Silva DMGV da, Boell JEW, Lopes SGR, Souza SS de. Rede de apoio a pessoas com deficiência física. Rev. Enferm. UERJ. 2017; 25:e18758. DOI: http://dx.doi.org/10.12957/reuerj.2017.18758

19. Nóbrega VCF, Melo RHV, Diniz ALTM, Vilar RLA. As redes sociais de apoio para o Aleitamento Materno: uma pesquisa-ação. Saúde debate. 2019; 43 (121): 429-440. http://dx.doi.org/10.1590/01031104201912111.

20. Cassidy JD, Boyle E, Carroll LJ. Population-Based, Inception Cohort Study of the Incidence, Course, and Prognosis of Mild Traumatic Brain Injury After Motor Vehicle Collisions. Arch. Phys. Med. Rehabil. 2014; 95 (3 Suppl2): S278-85. DOI: 10.1016/j.apmr.2013.08.295

21. Sadock BJ, Sadock VA, Ruiz P. Compêndio de psiquiatria: ciência do comportamento e psiquiatria clínica. $11^{\circ}$ ed. Porto Alegre, 2017.

22. Cavalcante FG, Morita PA, Haddad SR. Sequelas invisíveis dos acidentes de trânsito: o transtorno de estresse pós-traumático como problema de saúde pública. Ciênc. Saúde Coletiva. 2009; 14 (5):1763-1772. https://doi.org/10.1590/S1413-81232009000500017

23. Calliga MCNS, Porto L A. Which people with traumatic paraplegia return to work? Ciênc. saúde coletiva. 2019; 24 (6): 2341-2350. https://doi.org/10.1590/1413-81232018246.15682017.

24. Samoborec S, Ayton D, Ruseckaite R, Winbolt G, Evans SM. System complexities affecting recovery after a minor transport-related injury: The need for a person-centred approach. J Rehabil Med. 2019; 51 (2): 120126. doi: $10.2340 / 16501977-2500$. 